\title{
Analyses of Oxyanion Materials by Prompt Gamma Activation Analysis
}

\author{
D. L. Perry, G. A. English, R. B. Firestone, and K.-N. Leung \\ Lawrence Berkeley National Laboratory, Berkeley, CA 94720 USA \\ G. Garabedian \\ Lawrence Livermore National Laboratory, Livermore, CA 94550 USA \\ G. L. Molnar and Zs. Revay \\ Institute for Isotope and Surface Chemistry, Budapest H-1525 HUNGARY
}

Prompt gamma activation analysis (PGAA) has been used to analyze metal ion oxyanion materials that have multiple applications, including medicine, materials, catalysts, and electronics. The significance for the need for accurate, highly sensitive analyses for the materials is discussed in the context of quality control of end products containing the parent element in each material. Applications of the analytical data for input to models and theoretical calculations related to the electronic and other properties of the materials are discussed. 


\section{Introduction}

Elemental analyses for a wide array of elements in the Periodic Table are of extreme value for a wide range of purposes, including trying to gain a knowledge of materials failure when it occurs, modeling the electronic, magnetic, and chemical properties, and assessing and verifying quality control of the purity of the materials in which they are found. Both the elements and their compounds are useful for an extremely wide variety of applications in chemistry and materials science, including applications that are dependent on the elements' magnetic, electronic, and physical properties as well as their ability to form compounds and complexes. In obtaining precise analytical data for materials, the analyst may need a technique which will give really good, high-quality analytical data while preserving the integrity of the samples for archival purposes.

The materials that have been analyzed in the present study represent an eclectic group of elements that are important from a wide number of standpoints. Additionally, in many cases, the counteranions associated with the central elements in the materials can be of extreme importance in the compound's role as synthetic precursors for other materials where the original materials or compounds have really good advantages as starting materials. Beryllium nitrate, for example, can be used as a starting material for the synthesis of beryllium oxide, ${ }^{1}$ which is used in an extremely wide variety of applications ranging from sophisticated electronic materials ${ }^{2}$ to dopants in gemstones ${ }^{3}$ to dental materials. ${ }^{4}$ It also represents, however, an element whose toxicity in humans $^{5,6}$ makes it extremely important as an analytical target due to many applications that impact both humans and the environment. Magnesium sulfate is 
widely used in medical and biomedical applications, ${ }^{7}$ while scandium and its compounds (including the sulfate analyzed here) act as precursors in the synthesis of materials as well as serve as materials on their own. ${ }^{8}$ Antimony is used in a wide variety of applications employing mixed elemental oxides, including catalysts, alloys, and magnetic materials. ${ }^{9}$ Gallium is used for a wide assortment of electronic materials such as gallium arsenide, ${ }^{10}$ many of which demand extremely high purity and quality control. Lead has applications in materials including powders, electronic devices, and ceramics $^{11}$ and also an extensive biochemistry and toxicology, ${ }^{12}$ all areas of interest areas necessitating the ability to obtain definitive analyses. Thorium and uranium ${ }^{13}$ are major members of the actinide, or $5 f$ block, of elements in the Periodic Table that are used as nuclear fuels, catalysts, and many other applications. ${ }^{14}$

Neutron induced Prompt Gamma Activation Analysis (PGAA) is a nondestructive, self-calibrating, radio-analytical method capable of simultaneously identifying nearly the entire Periodic Table. It exploits the prompt capture gamma rays themselves, while Neutron Activation Analysis (NAA) utilizes the delayed gamma rays from the radioactive daughter nucleus and is thus able to detect every element in the Periodic Table from hydrogen through uranium. The method has been applied to materials science, chemistry, geology, mining, archaeology, environment, food analysis, medicine and other areas. Development of high flux neutron generators and a new analytical PGAA database make it possible to apply PGAA/NAA techniques without requiring a nuclear reactor. The nuclear reactions to form the gamma ray lines are independent of the physical form of the sample being analyzed, thus allowing the elemental composition of solids, liquids, and gases to be obtained. Also, the technique 
allows for the non-destructive analyses of samples with no prior chemical or other type of physical or experimental preparation.

The present report describes the application of PGAA to the analysis of a wide array of chemically-based materials for which total characterization data, including those for trace contaminants, are often required. The technique also is discussed with respect to its use in monitoring trace amounts of elements used in the syntheses and processing of other materials that use such rare earths as precursor materials or as the desired final product.

\section{EXPERIMENTAL}

\section{Materials}

The elemental oxyanion samples were analyzed using prompt-gamma activation analysis as previously described. ${ }^{15-17}$ The compounds of beryllium, magnesium, scandium, antimony, gallium, lead, thorium, and uranium were obtained commercially as being reagent grade.

\section{PGAA Method}

The neutron-induced prompt gamma activation analyses (PGAA) were performed at the Institute for Isotope and Surface Chemistry, Budapest, Hungary, which has been described previously. ${ }^{15-17}$ The Budapest Reactor is a water-cooled, water-moderated research reactor with a thermal power of $10 \mathrm{MW}$. A beam of lowenergy neutrons is transported for approximately 35 meters from the reactor core by a curved neutron guide fabricated from a glass coat with a nickel reflector. The promptgamma experimental apparatus is located at the end of the guide where the energy of the neutrons is less than that of thermal neutrons due to the higher energy neutrons not 
being reflected. The thermal-equivalent effective flux is approximately $2.5 \times 10^{6}$ $\mathrm{cm}^{-2} \mathrm{~s}^{-1}$ at the target position.

The samples were placed directly in the beam that had been collimated to an area of $2 \times 2 \mathrm{~cm}$. The determined chemical composition of the sample was an average value for the entire irradiated volume of the sample due to the almost total transparency of the sample to neutrons. The prompt gamma rays were detected by a detector system ${ }^{15}$ whose main component was a Canberra high-purity germanium (HPGe) detector which was surrounded by a bismuth germanate (BGO) scintillator annulus used to reject Compton-scattered photons. The detector assembly could be moved to variable lengths from the target, with the main detector being moved to within as close as $12 \mathrm{~cm}$ to the target. Complete details of the experimental arrangement and detector system have been published elsewhere. ${ }^{16}$

Spectra for the samples were collected using a 16,000 channel multichannel analyzer from Canberra, Model No. S100 MCA The energy and efficiency calibrations for the system were made using known $\gamma$-lines emitted by radioactive sources and $(\mathrm{n}, \gamma)$ reactions. The collected spectra of the rare earth oxides were analyzed by "Hypermet PC," a $\gamma$-spectrum analysis program developed at our laboratory at the Institute for Isotope and Surface Chemistry in Budapest. ${ }^{17}$

\section{Element Identification}

The elemental identification involved with these samples is based on the nuclear database here at the Institute for Isotope and Surface Chemistry, Budapest, Hungary. The elements are identified according to the energy values of their most intense prompt-gamma peaks. The reliability of the element identification is controlled through different statistical parameters which are derived from the deviations of 
measured energy and intensity values from literature values. ${ }^{18}$ The intensity ratios between the different gamma peaks must also be considered, along with the possible background lines. The background gamma rays mostly originate from the $(n, \gamma)$ reactions in the surrounding material. The most important sources are from oxygen and nitrogen in the air, iron and aluminum in the equipment's material, and fluorine from the Teflon packaging material surrounding the samples.

\section{Determination of Chemical Composition}

The detected gamma-ray intensity, represented by the peak area $\left(A_{E}\right)$, is directly proportional to the mass of a given chemical element, and the measuring time, $t$. Hence,

$$
m=\frac{1}{S} \cdot \frac{A_{E}}{t}
$$

where

$$
S=\frac{N_{A}}{M} \cdot \theta \cdot \sigma_{o} \cdot I_{\gamma} \cdot \Phi_{o} \cdot \varepsilon\left(E_{\gamma}\right)
$$

is the analytical sensitivity, expressed in units of counts $\mathrm{s}^{-1} \mathrm{mg}^{-1}$. It is proportional to the neutron capture cross-section of the nucleus $\sigma_{0}$, the isotopic abundance $\theta$ and the gamma yield $I_{\gamma}$, which are nuclear constants, as well as to the neutron flux $\Phi_{0}$ and the detector efficiency $\varepsilon\left(\mathrm{E}_{\gamma}\right)$ - which are characteristics of the measuring system.

The mass ratio for an element " $\mathrm{x}$ " can be determined according to the following equation:

$$
\frac{m_{x}}{m_{R}}=\frac{A_{E, x}}{A_{E, R}} \cdot \frac{k_{0, C}(R)}{k_{0, C}(x)} \cdot \frac{\varepsilon_{R}\left(E_{\gamma}\right)}{\varepsilon_{x}\left(E_{\gamma}\right)}
$$

where $\mathrm{R}$ is an arbitrary reference element contained in the sample. This ratio is independent of the neutron flux, it depends only on nuclear constants and the detector 
efficiency. The latter are known with good accuracy. ${ }^{19}$ The $k_{0}$-factors were determined by internal standardization measurements. The masses were calculated according to Eqns. (1)-(3). The gamma lines used and the corresponding $k_{0}$-factors are listed in Ref. 19. The possible interferences between different gamma peaks were individually examined, and the peaks affected by spectral interference were neglected.

The total uncertainties (standard deviations) were calculated from the statistical (counting) uncertainties of the peak areas, the uncertainties of the $k_{0}$-factors and the uncertainties of the detector efficiencies. As the last two typically have standard deviations of a few per cent, the total uncertainty is mainly determined by the counting statistics reflected in the analytical sensitivities.

\section{Detection Limits}

For the un-detected elements, detection limits $\left(C_{L}\right)$ were calculated from the spectra themselves from Eqn. 4, where $\sigma_{\mathrm{B}}$ is the standard deviation of the baseline, and $\mathrm{S}$ is the sensitivity for a given element. The baseline is a complex function that is calculated by the Hypermet PC

$$
C_{\mathrm{L}}=3 \sigma_{\mathrm{B}} / \mathrm{S}
$$

automatically for each region. $\sigma_{\mathrm{B}}$ is the constant part of the function.

\section{Measurements}

Elemental compositions of the samples were obtained by means of PGAA. The oxyanion compounds were run as solid powders as received. Compton suppressed prompt gamma-ray spectra were measured as usual. The samples were irradiated for $\sim 900$ to 61,000 seconds. 


\section{RESULTS AND DISCUSSION}

From a materials standpoint, the production quality and purity of a material are extremely important with respect to a whole analysis of the material. Because of different feedstocks of raw materials---such as ores--- used for the production of many batches worldwide of chemicals and materials from the parent elements used to make other materials, there is usually a wide assortment of impurities and levels of impurities observed in the final product. This is possibly due to the processing and separation scheme used to extract the parent elements of each material from their ores and subsequent processing and purification. A thorough analytical knowledge of solid matrix elements can be very important from several standpoints, with either the element of interest being the primary element of the bulk material matrix itself, or a contaminant in the material matrix. Indeed, entire books address the subject of such chemical defects and impurities in a wide variety of materials. ${ }^{20,21}$ Many times, it is important to have a precise and very accurate analysis of a material with respect to the concept of quality control. This is true in the materials manufacturing sector, where the bulk material must have extremely low levels of impurities because of the impurities' possible effects on the performance characteristics of a particular material. It also is beneficial to know the levels of contaminant elements in industrial batches of materials in general so as to be able to use this knowledge to understand the causes and postulate mechanisms in case of material failures.

The need for a detailed knowledge of contaminants in solid matrices also is extremely helpful in the development of models and theoretical calculations of processes involving electronic materials. In the case of semiconductors, for example, contaminants of different elements are critical to both the quality and performance of 
the material. This leads to a variety of questions with respect to the nature and number of these elemental contaminants in the lattice. What is the concentration, coordination sphere (types and number of next nearest atoms), oxidation state, and electronic/magnetic state of each contaminant? Also, are there electronic and magnetic interactions among contaminant elements in the lattice? All of these questions are applicable to manganese and iron shown in Table 2, for example.

\section{CONCLUSIONS}

Prompt gamma activation analysis (PGAA) has been used to analyze metal ion oxyanion materials for the determination of small dopant amounts of elemental impurities. The technique proves to be effective as an analytical approach in which the original sample is preserved with no damage or loss of mass from sampling, giving an investigator an analytical method that is free from additional chemistry, separations procedures, or scientific labor to prepare the sample for analysis. Because of this, the sample is available for archival storage after the analysis.

\section{ACKNOWLEDGMENTS}

This work was performed for the U. S. Department of Energy under Contract

Number DE-AC02-05CH11231 and the U. S. Hungarian Joint Fund under Program No. 429.

\section{REFERENCES}

1. D. J. KACZYNSKI, Kirk-Othmer Encyclopedia of Chemcial Technoogy, John Wiley \& Sons, New York, 2002. 
2. V. S. KIJKO, S. V. GLADKOVSKY, I. A. DMITRIEV, A. A. SOFRONOV., Y. N. MAKURIN, A. L. IVANOVSKY, Symposium A, Fall Meeting of the E-MRS [European Materials Research Society], 2003.

3. J. L. EMMETT, K. SCARRATT, S. F. McCLURE, T. MOSES, T. R. DOUTHIT, R. HUGHES, S. NOVAK, J. E. SHIGLEY, W. WANG, O. BORDELON, R. E. KANE, Gems \& Gemology, 39(2004) 84.

4. K. LEINFELDER, J. Amer. Dent. Assoc., 128(1985) 37.

5. D. KRIEBEL, J. D. BRAIN, N. L. SPRINCE, H. KAZEMI, Am. Rev. Respir. Dis., 137(1988) 464.

6. E. C. McCANLIES, K. KREISS, M. ANDREW, A. WESTON, Am. J. Epidemiol.,157 (2003) 388.

7. G. HSIAO, M.-Y. SHEN, D.-S. CHOU, C.-H. LIN, T.-F. CHEN, J.-R. SHEU, J. Biomed. Sci., 11 (2004) 19.

8. J.-G. LI, T. IKEGAMI, T. MORI, J. Mater. Res., 18 (2003) 1816.

9. R. GRAU-CRESPO, N. H. de LEEUW, C. R. A. CATLOW, J. Mater. Chem., 13 (2003) 2848.

10. M. J. HOWES, D. V. MORGAN, Gallium Arsenide: Materials, Devices, and Circuits, John Wiley \& Sons, New York, 1985.

11. S. W. LYONS, Y. XIONG, T. L. WARD, T. T. KODAS, S. E. PRATSINIS, J. Mater. Res., 7 (1996) 3333.

12. H. A. GODWIN, Curr. Opin. Chem. Biol., 5 (2001) 223.

13. G. T. SEABORG, L. R. MORSS, J. J. KATZ (Eds.), Chemistry of the Actinide Elements-Second Edition, Kluwer Academic Publishers, Dordrecht, 1986.

14. R. G. BAUTISTA, B. MISHRA, R. G. BAUTISTA (Eds.), Rare Earths and Actinides: Science, Technology, and Applications IV, Warrendale, PA, 2000.

15. G. L. MOLNAR, T. BELGYA, L. DABOLCZI, B. FAZEKAS, A. VERES, I. BIKIT, J. OSTOR, J. Radioanal. Nucl. Chem., 215 (1997) 111.

16. T. BELGYA, ZS. REVAY, B. FAZEKAS, I. HEJJA, L. DABOLCZI, G. L. MOLNAR, Z. KISS, J. OSTOR, GY. KASZAS, in Proceedings of the $9^{\text {th }}$ International Symposium on Capture Gamma-Ray Spectroscopy and Related Topics, G. L. MOLNAR, T. BELGYA, (Eds.), Springer Hungarica, Budapest, 1997, p. 826; also, see the following Website at 
http://www.iki.kfki.hu/nuclear/ for photographic and schematic details of the experimental facility.

17. D. L. PERRY, R. B. FIRESTONE, G. L. MOLNAR, ZS. REVAY, ZS. KASZTOVSZKY, R. C. GATTI, J. Anal. At. Spectrom., 17 (2002) 32.

18. G. L. MOLNAR, ZS. REVAY, T. BELGYA, ZS. KASZTOVSZKY, R. B. FIRESTONE, Appl. Radiat. Isot., 53 (2000) 527.

19. G. L. MOLNAR, ZS. REVAY, R. L. PAUL, R. M. LindSTROM, Appl. Radioanal. Nucl. Chem., 234 (1998) 21.

20. R. J. D. TILLEY, Principles and Applications of Chemical Defects, CRC Press, Boca Raton, FL, 1998.

21. V. I. Fistul, Impurities in Semiconductors: Solubility, Migration, and Interactions, CRC Press, Boca Raton, FL, 2004.

Table 1. Analysis conditions of metal oxyanion materials by PGAA 


\begin{tabular}{llcr}
\hline Element (Anion) & \multicolumn{1}{c}{ Sample } & Measurement Time, s & Total Counts \\
\hline & & & \\
Beryllium (Nitrate) & $\mathrm{Be}\left(\mathrm{NO}_{3}\right)_{2} \cdot 3 \mathrm{H}_{2} \mathrm{O}$ & 64,050 & 487,313 \\
Magnesium (Sulfate & $\mathrm{MgSO}{ }_{4} \cdot 7 \mathrm{H}_{2} \mathrm{O}$ & 15,806 & 548,355 \\
Scandium (Sulfate) & $\mathrm{Sc}_{2}\left(\mathrm{SO}_{4}\right)_{3}$ & 12,000 & $3,981,050$ \\
Antimony (Sulfate) & $\mathrm{Sb}_{2}\left(\mathrm{SO}_{4}\right)$ & 8404 & $2,386,684$ \\
Gallium (Nitrate) & $\mathrm{Ga}\left(\mathrm{NO}_{3}\right)_{3} \cdot 8 \mathrm{H}_{2} \mathrm{O}$ & 5674 & 140,782 \\
Lead (Nitrate) & $\mathrm{Pb}\left(\mathrm{NO}_{3}\right)_{2}$ & 43.920 & 337,998 \\
Thorium (Nitrate) & $\mathrm{Th}_{\left(\mathrm{NO}_{3}\right)_{4} \cdot 4.5 \mathrm{H}_{2} \mathrm{O}}$ & 61,903 & $2,586,834$ \\
Uranium (Acetate) & $\mathrm{UO}_{2}\left(\mathrm{C}_{2} \mathrm{H}_{3} \mathrm{O}_{2}\right)_{2} \cdot 2 \mathrm{H}_{2} \mathrm{O}$ & 67,811 & $29,641,663$ \\
\hline
\end{tabular}

Table 2. Contaminant elements and concentrations found in oxyanion materials

\begin{tabular}{|c|c|c|}
\hline Element (Anion) & Sample & Contaminants \\
\hline Beryllium (Nitrate) & $\mathrm{Be}\left(\mathrm{NO}_{3}\right)_{2} \cdot 3 \mathrm{H}_{2} \mathrm{O}$ & $\mathrm{B}, 0.39 \mathrm{ppm} ; \mathrm{Cl}, 14(3) \mathrm{ppm} ; \mathrm{Cd}, 0.14 \mathrm{ppm}$ \\
\hline Magnesium (Sulfate) & $\mathrm{MgSO}_{4} \cdot 7 \mathrm{H}_{2} \mathrm{O}$ & $\mathrm{Cl}, 17(2) \mathrm{ppm} ; \mathrm{Fe}, 0.070(14) \% ; \mathrm{Sm}, 0.6(2) \mathrm{ppm}$ \\
\hline Scandium (Sulfate) & $\mathrm{Sc}_{2}\left(\mathrm{SO}_{4}\right)_{3}$ & No minor elements detected \\
\hline Antimony (Sulfate) & $\mathrm{Sb}_{2}\left(\mathrm{SO}_{4}\right)$ & No minor elements detected \\
\hline Gallium (Nitrate) & $\mathrm{Ga}\left(\mathrm{NO}_{3}\right)_{3} \cdot 8 \mathrm{H}_{2} \mathrm{O}$ & No minor elements detected \\
\hline Lead (Nitrate) & $\mathrm{Pb}\left(\mathrm{NO}_{3}\right)_{2}$ & $\mathrm{Fe}, 430(100) \mathrm{ppm}$ \\
\hline Thorium (Nitrate) & $\mathrm{Th}\left(\mathrm{NO}_{3}\right)_{4} \cdot 4.5 \mathrm{H}_{2} \mathrm{O}$ & $\mathrm{Mn}, 0.020(5) \%$ \\
\hline Uranium (Acetate) & $\mathrm{UO}_{2}\left(\mathrm{C}_{2} \mathrm{H}_{3} \mathrm{O}_{2}\right)_{2} \cdot 2 \mathrm{H}_{2} \mathrm{O}$ & No minor elements detected \\
\hline
\end{tabular}

Figure 1. The PGAA spectrum of $\mathrm{Th}\left(\mathrm{NO}_{3}\right)_{5} \cdot 4.5 \mathrm{H}_{2} \mathrm{O}$ 


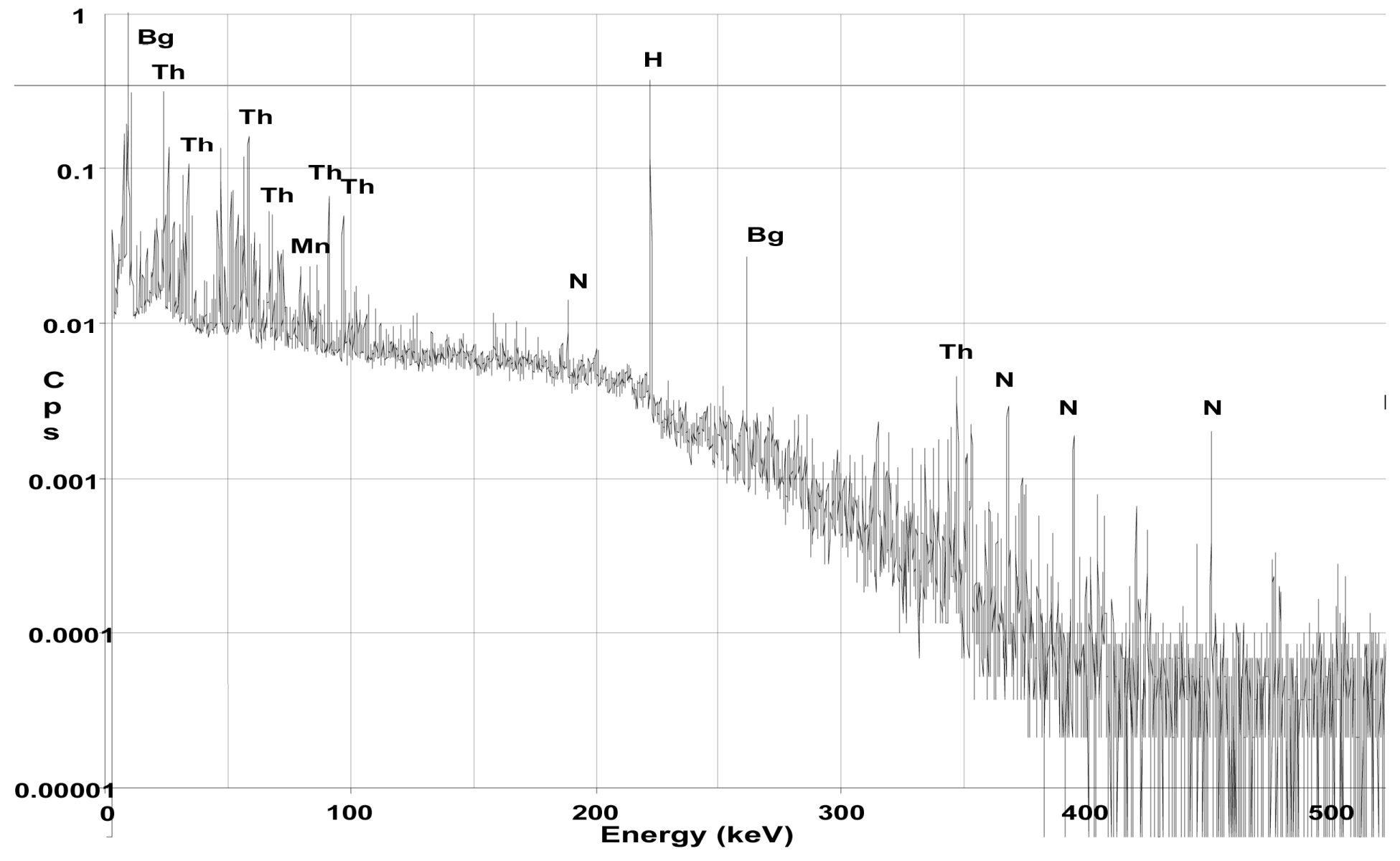

